\title{
A Design Approach to Wireless High-Power Transfer to Multiple Receivers with Asymmetric Circuit
}

\author{
Sabriansyah Rizqika Akbar \\ Department of Materials and Informatics, \\ Interdisciplinary Graduate School of Agriculture \\ and Engineering \\ University of Miyazaki \\ 1 Chome-1 Gakuenkibanadainishi, Miyazaki, \\ 889-2192 \\ Japan
}

\author{
Ichijo Hodaka \\ Department of Environmental Robotics, \\ Faculty of Engineering \\ University of Miyazaki \\ 1 Chome-1 Gakuenkibanadainishi, Miyazaki, \\ 889-2192 \\ Japan
}

Received: June 12, 2020. Revised: January 30, 2021. Accepted: February 12, 2021. Published: February 16, 2021.

\begin{abstract}
Wireless Power Transfer (WPT) system commonly compensates by a symmetric pair of inductor and capacitor on the primary-secondary circuits to use the idea of resonance. It should be noticed that an additional component compensation on the common WPT circuit is able to affect the power transferred to the load. Although it is useful to wirelessly transfer power to multiple receivers, the complexity of the system will increase with the number of receivers as well as the system loses symmetry, and then, it would be difficult to design high power transfer system. This study explores the WPT circuit compensated with a single capacitor in the primary side to transfer high power to dual receivers. Using a single capacitor on the primary side makes the circuit asymmetry, so the idea of resonance cannot be used. To find operating points that maximize transferred power, this paper uses a mathematical optimization technique with several design variables. The NSGA-II (Non-dominated Sorting Genetic Algorithm II) is used to optimize the design variables of the mathematical system model. The results show that the proposed system is able to attain high power even though using only a single capacitor compensation without the idea of resonance.
\end{abstract}

Keywords-Optimization, wireless power transfer resonance.

\section{INTRODUCTION}

$\mathrm{W}$ IRELESS Power Transfer (WPT) supplies electric power to an electric device without wires. Nowadays, WPT has been implemented in many practical applications, such as in electric vehicles [1], biomedical devices [2] [3], and electronic appliances [4]. The increasing demand for electronic appliances increases the WPT usage since many companies want to avoid complex wire connections. For now, and the future challenge, WPT is required to be able to meet the need to charge multiple devices at once [5-8].
The architecture and optimization fields are considered as a research hotspot in WPT research [9]. The common WPT architecture uses a capacitor compensation on their primary and secondary circuits [10] to achieve high power. Therefore, many works use the idea of resonance as a requirement to obtain the operating frequency [11]. Further, impedance matching [12] and optimization techniques [13] have been proposed to make a high-power WPT system.

The common WPT circuit using the idea of resonance does not always obtain high power [14]. Adding components such as capacitors to the receiver to compensate WPT circuit can increase the equivalent series resistance so that it can affect the power and efficiency of the WPT system [15] [16] [17]. Furthermore, the addition of capacitors to the multiple receivers makes the WPT circuit more complicated as the number of receivers increases.

For this reason, we propose to use a single capacitor compensation on the primary side of the WPT system. This proposed system can disregard the capacitance parameters and its parasitic resistance on the secondary side. The challenge of exploring this circuit is it lacks symmetry, so it cannot use the idea of resonance. Hence, another approach to achieve high-power optimal operating points needs to be addressed.

Many other studies on WPT are based on the idea of resonance [10] [11]. Then, they suppose a symmetric circuit, that is, to use a pair of capacitors and inductors for both primary and secondary sides. However, the situation of symmetry would be violated if we suppose multiple targets. Moreover, it has not been proven and is still an open question that violating the symmetry and accepting non-resonance would be poor strategies. The main difficulty of the question comes from the large flexibility of circuit topology if we extend our analysis to 
asymmetric circuits. To overcome the difficulty, we propose an asymmetric circuit without a capacitor on the secondary sides and make the optimization process easier.

In this paper, we present our approach in several steps. Initialized by analyzing the circuit equations, we obtain transfer function as our system model [18-20]. Our system model contains two transfer functions for each of the load receivers. Thus, both transfer function is used as the objective function and the problem set is defined from the selection of design variables. We will confirm our results by conducting LTSPICE simulation for each of the optimization scenarios.

\section{SySTEM MOdEL}

Fig. 1 shows our proposed WPT circuit which only uses a single capacitor to transfer power to two receivers. In the primary circuit, the components consist of $u$ as the voltage of voltage source and its resistance $R_{s}$, the capacitor $C$, the primary coil $L_{1}$, and its parasitic resistance $R_{1}$. The first receiver consists of the first receiver coil $L_{2}$ and its parasitic resistance $R_{2}$ and load $R_{L 1}$. In the second receiver, the components consist of a second receiver coil $L_{3}$ and its parasitic resistance $R_{3}$ and load $R_{L 2}$. The mutual inductance between the primary circuit with the first receiver is symbolized with $M_{1}$, and the mutual inductance between the primary circuit and the second receiver is notated with $M_{2}$. In this circuit, we also consider the cross-coupling mutual inductance between the first and second receiver as $M_{3}$.

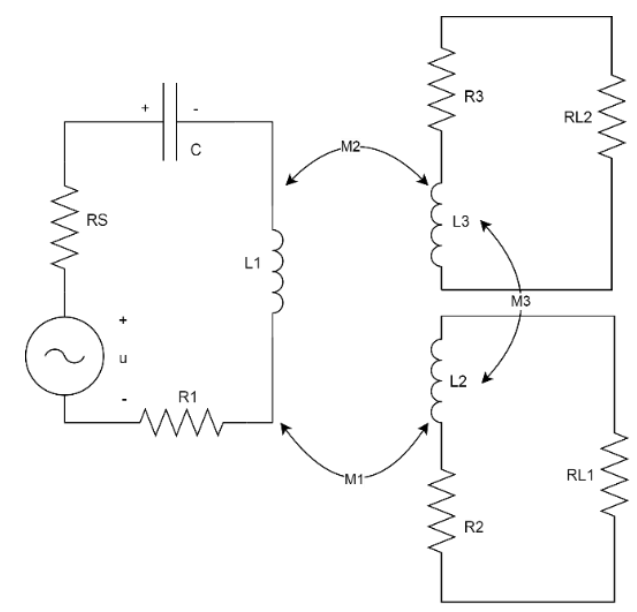

Fig. 1. Proposed Single Capacitor Dual Receivers WPT Circuit

With Fig. 1 we model our system starting with the Kirchhoff voltage and current laws described in (1).

$$
\begin{aligned}
& u=i_{1} R_{S}+i_{1} R_{1}+L_{1} \frac{d i_{1}}{d t}+M_{1} \frac{d i_{2}}{d t}+M_{2} \frac{d i_{3}}{d t}+v_{1} \\
& i_{1}=C \frac{d v_{1}}{d t} \\
& 0=i_{2} R_{L 1}+i_{2} R_{2}+L_{2} \frac{d i_{2}}{d t}+M_{1} \frac{d i_{1}}{d t}+M_{3} \frac{d i_{3}}{d t} \\
& 0=i_{3} R_{L 2}+i_{3} R_{3}+L_{3} \frac{d i_{3}}{d t}+M_{2} \frac{d i_{1}}{d t}+M_{3} \frac{d i_{2}}{d t}
\end{aligned}
$$

By $v_{1}, i_{1}, i_{2}, i_{3}$ are the state-space variables, $u$ is the input, and $y$ is the output, the state-space representations are described as (2).

$$
\begin{aligned}
& \dot{x}=A x+B u \\
& y_{L 1}=C_{L 1} x+D u \\
& y_{L 2}=C_{L 2} x+D u
\end{aligned}
$$

where

$$
\begin{aligned}
& \left\lfloor\begin{array}{l}
\frac{d v_{1}}{d t} \\
\frac{d i_{1}}{d t} \\
\frac{d i_{2}}{d t} \\
\frac{d i_{3}}{d t}
\end{array}\right\rfloor=A\left[\begin{array}{l}
v_{1} \\
i_{1} \\
i_{2} \\
i_{3}
\end{array}\right]+B u \\
& y_{L 1}=C_{L 1}\left[\begin{array}{l}
v_{1} \\
i_{1} \\
i_{2} \\
i_{3}
\end{array}\right]+D u \quad y_{L 2}=C_{L 1}\left[\begin{array}{l}
v_{1} \\
i_{1} \\
i_{2} \\
i_{3}
\end{array}\right]+D u \\
& C_{L 1}=\left[\begin{array}{llll}
0 & 0 & -R_{L 1} & 0
\end{array}\right] \quad C_{L 2}=\left[\begin{array}{llll}
0 & 0 & 0 & -R_{L 2}
\end{array}\right] \\
& D=0
\end{aligned}
$$

The transfer functions from $u$ to $y_{L 1}$ and $y_{L 2}$ are respectively given by:

$$
\begin{aligned}
G_{L 1}(s) & =C_{L 1}(s I-A)^{-1} B+D \\
& =\frac{C R_{L 1} s^{2}\left(M_{1} R_{3}+M_{1} R_{L 2}+s\left(L_{3} M_{1}-M_{2} M_{3}\right)\right)}{\Delta} \\
G_{L 2}(s) & =C_{L 2}(s I-A)^{-1} B+D \\
& =\frac{C R_{L 2} s^{2}\left(M_{2} R_{2}+M_{2} R_{L 1}+s\left(L_{2} M_{2}-M_{1} M_{3}\right)\right)}{\Delta}
\end{aligned}
$$

where

$$
\begin{aligned}
& \Delta=C s^{4}\left(L_{1} L_{2} L_{3}-L_{1} M_{3}^{2}-L_{2} M_{2}^{2}-L_{3} M_{1}^{2}+2 M_{1} M_{2} M_{3}\right) \\
& +C s^{3}\left(\begin{array}{l}
L_{1} L_{2} R_{3}+L_{1} L_{2} R_{L 2}+L_{1} L_{3} R_{2}+L_{1} L_{3} R_{L 1}+L_{2} L_{3} R_{1} \\
+L_{2} L_{3} R_{S}-M_{1}^{2} R_{3}-M_{1}^{2} R_{L 2}-M_{2}^{2} R_{2}-M_{2}^{2} R_{L 1}-M_{3}^{2} R_{1}-M_{3}^{2} R_{S}
\end{array}\right) \\
& +s^{2}\left(\begin{array}{l}
C L_{1} R_{2} R_{3}+C L_{1} R_{2} R_{L 2}+C L_{1} R_{3} R_{L 1}+C L_{1} R_{L 1} R_{L 2}+C L_{2} R_{1} R_{3} \\
+C L_{2} R_{1} R_{L 2}+C L_{2} R_{3} R_{S}+C L_{2} R_{S} R_{L 2} \\
+C L_{3} R_{1} R_{2}+C L_{3} R_{1} R_{L 1}+C L_{3} R_{2} R_{S}+C L_{3} R_{S} R_{L 1}+L_{2} L_{3}-M_{3}^{2}
\end{array}\right) \\
& +s\left(\begin{array}{l}
C R_{1} R_{2} R_{3}+C R_{1} R_{2} R_{L 2}+C R_{1} R_{3} R_{L 1}+C R_{1} R_{L 1} R_{L 2} \\
+C R_{2} R_{3} R_{S}+C R_{2} R_{S} R_{L 2}+C R_{3} R_{S} R_{L 1} \\
+C R_{S} R_{L 1} R_{L 2}+L_{2} R_{3}+L_{2} R_{L 2}+L_{3} R_{2}+L_{3} R_{L 1}
\end{array}\right) \\
& +R_{2} R_{3}+R_{2} R_{L 2}+R_{3} R_{L 1}+R_{L 1} R_{L 2}
\end{aligned}
$$


Using sine wave input (5) ( $u_{0}$ is the amplitude of the input voltage), we obtain the steady-state voltage formula for the voltages over $R_{L 1}$ and $R_{L 2}$ as $y_{s s 1}$ and $y_{s s 2}$ respectively described as (6). Also, we describe the formula of steady-state power at $R_{L 1}$ and $R_{L 2}$ as $p_{s s 1}$ and $p_{s s 2}$ described in (7).

$$
\begin{aligned}
& u(t)=u_{0} \sin (\omega t) \\
& y_{s s 1}(t)=u_{0}\left|G_{L 1}(j \omega)\right| \sin \left(\omega t+\angle G_{L 1}(j \omega)\right) \\
& y_{s s 2}(t)=u_{0}\left|G_{L 2}(j \omega)\right| \sin \left(\omega t+\angle G_{L 2}(j \omega)\right) \\
& p_{s s 1}(t)=\frac{y_{s s 1}(t)^{2}}{R_{L 1}} \\
& p_{s s 2}(t)=\frac{y_{s s 2}(t)^{2}}{R_{L 2}}
\end{aligned}
$$

\section{OBJECTIVE FUNCTION AND OPTIMIZATION}

A WPT system can be designed using a couple of coils to deliver power wirelessly based on electromagnetic phenomena. However, this simplest WPT circuit cannot produce high power at the load receivers. Therefore, an additional component needs to be added in the primary or secondary circuit to obtain higher power. This method is commonly called a compensation method [21-22]. Thus, this study adds a single capacitor component on the primary side circuit and calculates the optimal capacitance value to obtain high power.

Common WPT circuit (in Fig. 2) [10-11] compensates the system with a capacitor installed on the primary circuit and each receiver side to obtain high power. Then, the idea of resonance is used to obtain operating frequency (8).

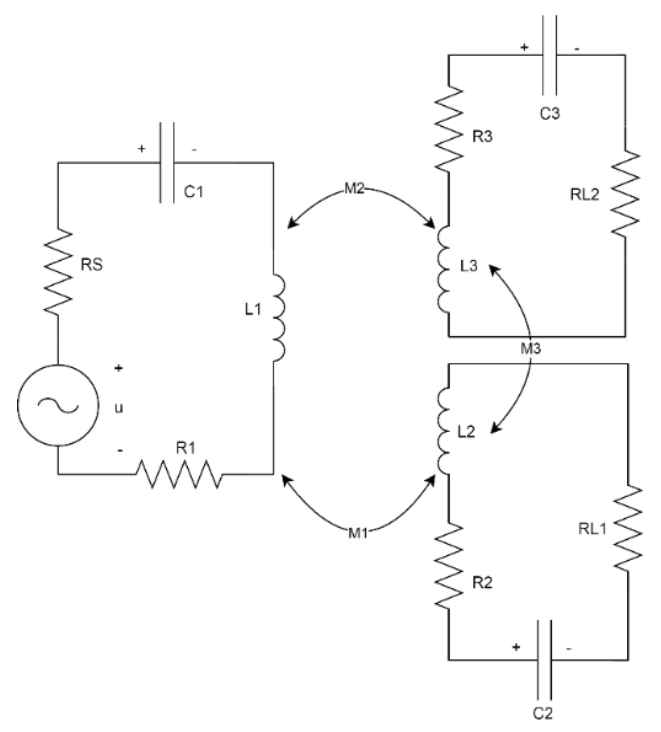

Fig. 2. Common Dual Receivers WPT Circuit with Capacitor Compensation in Each Receiver.

$$
\omega=\frac{1}{\sqrt{L_{1} C_{1}}}=\frac{1}{\sqrt{L_{2} C_{2}}}=\frac{1}{\sqrt{L_{3} C_{3}}}
$$

We should consider a method different from the common idea of resonance since our circuit lacks symmetry. Therefore, we will use an optimization technique with several choices of the design variables.

\section{A. Objective Functions}

Our study aims for the possible highest power transferred to the load receivers. The objective functions are taken from the steady-state power formulas described in equation (7). Thus, from (6) to (7), we express our multi-objective function as (9), where $f_{1}$ is proportional to the average power absorbed at $R_{L 1}$ and $f_{2}$ is proportional to the average power absorbed at $R_{L 2}$. The minus signs in (9) are for making the maximization problem to a minimization problem.

$$
\begin{aligned}
& f_{1}=-\frac{\left|G_{L 1}(j \omega)\right|^{2}}{R_{L 1}} \\
& f_{2}=-\frac{\left|G_{L 2}(j \omega)\right|^{2}}{R_{L 2}}
\end{aligned}
$$

The equations in (9) actually contain many parameters (13-parameters), and we have to choose design parameters among them depending on the situation. The WPT design variables were chosen based on the common WPT design requirement and approach, which are:

1. Design a high power WPT to work on the design when the variables selected were capacitance, frequency, and coupling coefficient.

2. Design a high power WPT to work on the design when the variables selected were capacitance, primary coil, and coupling coefficient.

3. Design a high power WPT to work on optimal operating point when the circuit component is fixed except for the capacitor. In this case, the design variables selected were capacitance and frequency.

\section{B. Design Variables: Capacitance, Frequency, and Coupling Coefficients}

Other than capacitance and frequency, the coupling coefficient plays an important part in the WPT system [13] [23][24]. In our situation, the coupling coefficients $K_{1}, K_{2}, K_{3}$ in (10) are likely to change depending on the gap size between the primary circuit coil and each coil on the receivers [25].

$$
K_{1}=\frac{M_{1}}{\sqrt{L_{1} L_{2}}} K_{2}=\frac{M_{2}}{\sqrt{L_{1} L_{3}}} K_{3}=\frac{M_{3}}{\sqrt{L_{2} L_{3}}}
$$

The coupling coefficient value is $0 \leq k<1$ (by assuming the common winding directions of coils). The coupling coefficients can be represented as air gap width between primary and secondary coils [26]. The value $k$ approaching to zero means a 
wide gap situation between coils and vice versa, where the transferred power tends to be small in general. However, the higher coupling coefficient (or narrow gap) is not always equal to the high power.

Our study conducted preliminary computation to get a better representation of this phenomenon. The analysis performed using (9) with numerical component values in TABLE I. where $K_{1}=K_{2}$ are free variables. In this computation, we assume there is no cross-coupling between receivers, therefore $K_{3}=0$. At this preliminary computation, we configured the $\omega=760$ kilorad/sec and $\mathrm{C}=62.3 \mathrm{nF}$.

TABLE I. NUMERICAL COMPONENTS VALUE

\begin{tabular}{|l|c|c|c|}
\hline Parameter & Value & Parameter & Value \\
\hline$L_{1}$ & $22 \mu \mathrm{H}$ & $R_{1}=R_{2}=R_{3}$ & $0.01 \Omega$ \\
\hline$L_{2}$ & $11 \mu \mathrm{H}$ & $R_{s}$ & $1 \Omega$ \\
\hline$L_{3}$ & $9 \mu \mathrm{H}$ & $R_{L 1}, R_{L 2}$ & $8 \Omega, 15 \Omega$ \\
\hline
\end{tabular}

Fig. 3 shows the performed computation and presents a result where $f_{1}$ and $f_{2}$ peak exist at some values of $K_{1}=K_{2}$. Therefore, a higher coupling coefficient does not always result in high power.

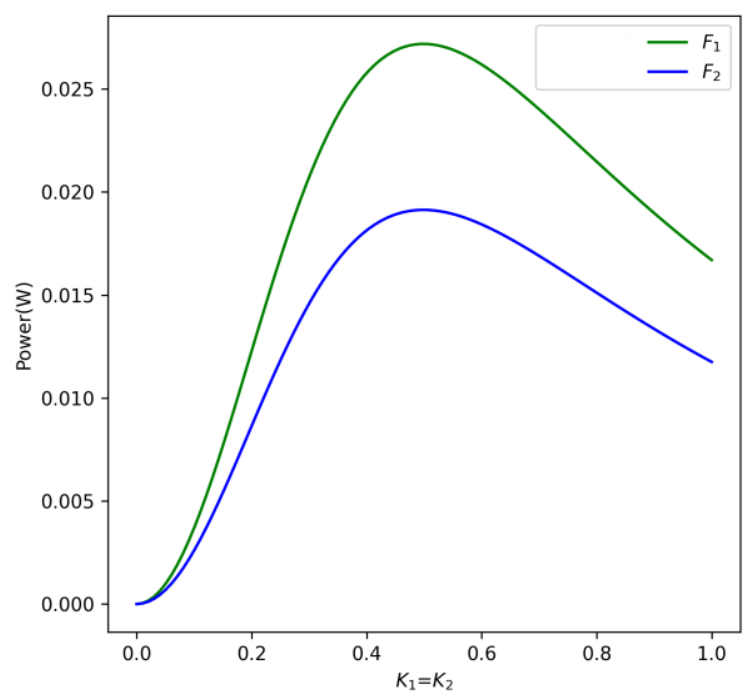

Fig. 3. Preliminary Computation Results of $f_{1}$ and $f_{2}$. With Numerical Values in TABLE I. where $K_{1}=K_{2}$ and $K_{3}=0$.

The situation can be easily complicated if the coupling coefficients $K_{1}$ and $K_{2}$ are not equal. A preliminary computation has been conducted to observe the situation. Using TABLE I. as the component values, we configured the $\omega=760$ kilorad/sec and $\mathrm{C}=62.3 \mathrm{nF}$ and $K_{2}$ is fixed at 0.3. Fig. 4 shows a situation where the second receiver's coupling coefficient $K_{2}=0.3$ and $K_{3}=0$, the gap between the primary circuit with the first receiver is getting narrower simulated by the $K_{1}$ is swept from 0-1. From Fig. 4, the power at the second receiver becomes lower when the first receiver gap is narrower to the primary circuit. Therefore, in this work, we assume the design meets the optimization requirement where $K_{12}=K_{1}=K_{2}$. Then, we describe the problem set as in (11).

$$
\begin{gathered}
\operatorname{Min} f_{1}\left(C, \omega, K_{12}\right) \\
\operatorname{Min} f_{2}\left(C, \omega, K_{12}\right) \\
1 p F \leq C \leq 0.1 F
\end{gathered}
$$

$100 \mathrm{rad} / \mathrm{sec} \leq \omega \leq 1 \cdot 10^{9} \mathrm{rad} / \mathrm{sec}$

$$
0.01 \leq K_{12} \leq 0.2
$$

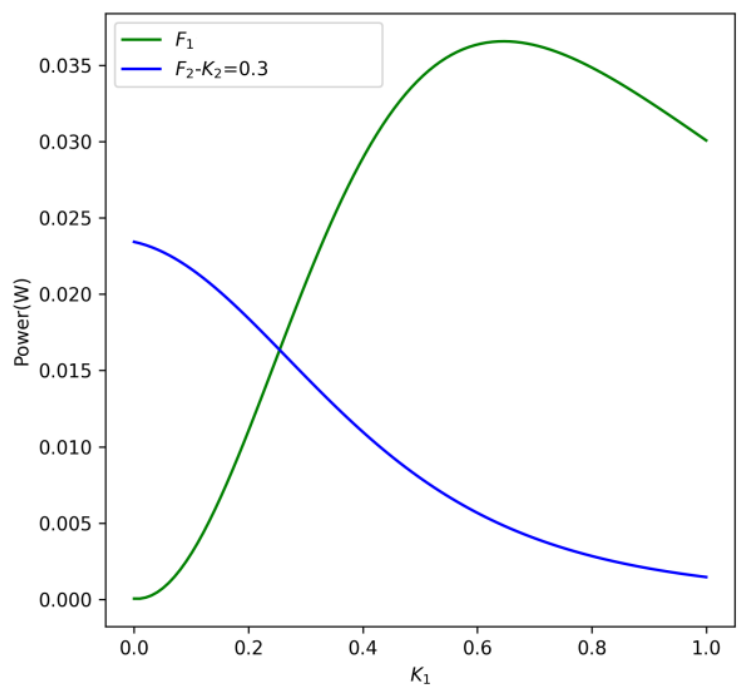

Fig. 4. Preliminary Computation Results of $f_{1}$ and $f_{2}$ with Numerical Values in TABLE I. where $K_{1}$ is a free variable, $K_{2}=0.3$ and $K_{3}=0.1$

\section{Design Variables: Capacitance, Primary Coil, and Coupling Coefficients}

Some WPT design requirement is needed to work on the ISM (Industrial, Scientific, and Medical) band which $6.78 \mathrm{MHz}$, 13.56 MHz, and so on [27-29]. When it comes to the fixed frequency, the parameter selection also considers the primary coils $L_{1}$ since the coils on the receiver's side should be in a fixed parameters condition. Therefore, in the ISM band WPT design, we propose to optimize capacitance, primary coil inductance, and coupling coefficients. Then the problem set is defined in (12). 


$$
\begin{gathered}
\operatorname{Min}_{1}\left(C, L_{1}, K_{12}\right) \\
\operatorname{Min} f_{2}\left(C, L_{1}, K_{12}\right) \\
1 p F \leq C \leq 0.1 F
\end{gathered}
$$

$100 \mathrm{rad} / \mathrm{sec} \leq \omega \leq 1 \cdot 10^{9} \mathrm{rad} / \mathrm{sec}$

$$
\begin{gathered}
1 \mu H \leq L_{1} \leq 100 \mu H \\
0.01 \leq K_{12} \leq 0.2
\end{gathered}
$$

\section{Design Variables: Capacitance and Frequency}

Our optimization also considers an optimization with two selection of design variables, where the selected two variables are the capacitance and frequency. Then, the problem set expresses as in (13).

$$
\begin{gathered}
\operatorname{Min}_{1}(C, \omega) \\
\operatorname{Min}_{2}(C, \omega) \\
1 \mathrm{pF} \leq C \leq 0.1 \mathrm{~F} \\
100 \mathrm{rad} / \mathrm{sec} \leq \omega \leq 1 \cdot 10^{9} \mathrm{rad} / \mathrm{sec}
\end{gathered}
$$

\section{E. Optimization Tools and Decision Making}

We run the optimization computation using Python Multi-Objective Optimization (PyMOO) [30] by using the NSGA-II [31]. The NSGA-II runs in 500 populations and 200 generations. Since our proposed approach is a multi-objective optimization, the solutions can be more than one and result in conflict between objectives. Therefore, a decision to select the best solutions need to be obtained [32].

In this study, we use the pseudo-weight vector approach provided by PyMOO to select the best solutions by configuring the weight of the objectives as in (14) where $i$ is the $i$-th objective function, $x$ is the design space variables and $M$ is the total of the objective functions.

$$
w_{i}=\frac{\left(f_{i}^{\max }-f_{i}(x)\right) /\left(f_{i}^{\max }-f_{i}^{\text {min }}\right)}{\sum_{m=1}^{M}\left(f_{m}^{\max }-f_{m}(x)\right) /\left(f_{m}^{\max }-f_{m}^{\text {min }}\right)}
$$

Then we decide the best operating point among the optimization solutions, which are selecting the fairest solutions described by giving the pseudo-weight for $f_{1}$ and $f_{2}$ solutions as 0.5 .

\section{RESUlts}

A. Optimization Results with Capacitance, Frequency, and Coupling Coefficients as Design Variables.

In this section, we conducted the optimization using $C, \omega$, and $K_{12}$ as design variables and problem set in (11) to obtain high power and optimal operating coupling coefficient. By substituting the TABLE I component values to the problem set, we got the objective function (15).

$$
f_{1}=\frac{f_{1 n}}{f_{d}} \quad f_{2}=\frac{f_{2 n}}{f_{d}}
$$

where:

\begin{tabular}{|c|c|c|c|c|c|}
\hline \multirow{2}{*}{$\begin{array}{c}\text { Decision } \\
\text { Making }\end{array}$} & \multicolumn{2}{|c|}{ Objective Values } & \multicolumn{3}{|c|}{ Design Values } \\
\hline & $\begin{array}{c}f_{1} \\
\text { (Watt) }\end{array}$ & $\begin{array}{c}f_{2} \\
\text { (Watt) }\end{array}$ & $\begin{array}{c}C \\
\text { (Farad) }\end{array}$ & $\begin{array}{c}\text { Frequency } \\
\text { (Hertz) }\end{array}$ & $K_{12}$ \\
\hline $\begin{array}{l}\text { Pseudo- } \\
\text { Weight } \\
0.5 f_{1} \\
0.5 f_{2}\end{array}$ & 0.09 & 0.15 & $10.2 \mathrm{n}$ & $343.01 \mathrm{k}$ & 0.16 \\
\hline $\begin{array}{l}\text { Smallest } \\
K_{12}\end{array}$ & 0.09 & 0.15 & $7.78 \mathrm{n}$ & $392.95 \mathrm{k}$ & 0.15 \\
\hline
\end{tabular}

The optimization results are presented in Fig. 5, where the NSGA-II obtained a total of 18 solutions. The results of the decision making are shown in TABLE II. Afterward, The LTSPICE AC analysis simulations (1 Volt-voltage of the voltage source) were performed to confirm TABLE II. results. The output of the simulations is processed and plotted in Fig. 6.

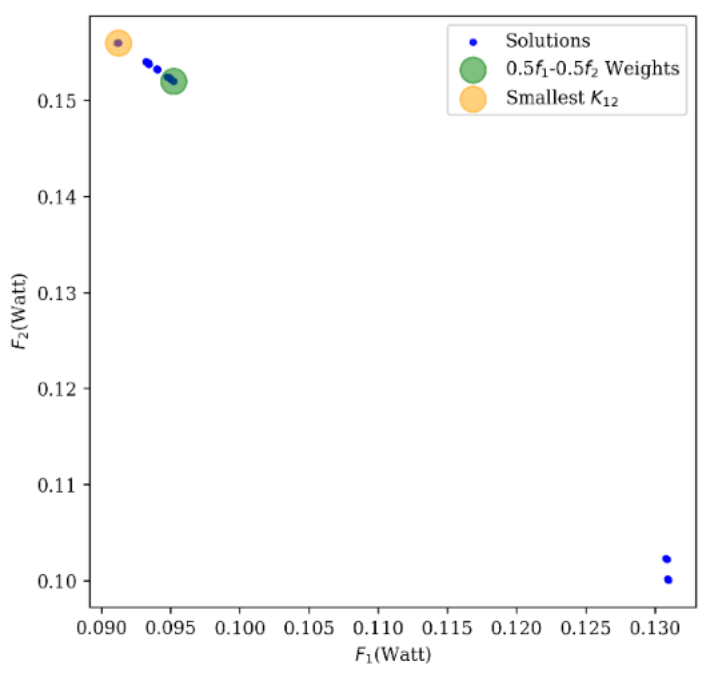

Fig. 5. Optimization Results for objective functions in (15) Using Numerical Values in TABLE I. where $K_{12}=K_{1}=K_{2}$ and $K_{3}=0$

TABLE II. FIG. 5 DECISION MAKING RESULTS 


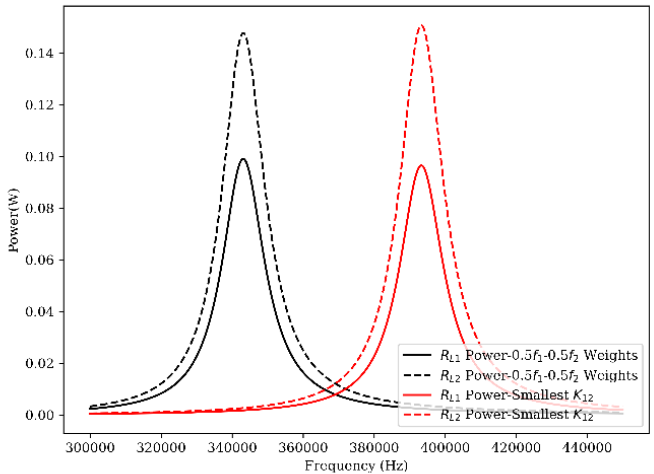

Fig. 6. LTSPICE Results Plotted using Python for obtained design values in TABLE II.

\section{B. Optimization Results with Capacitance, Primary Coil,} and Coupling Coefficients as Design Variables.

In this section, the optimization is performed with $6.78 \mathrm{MHz}$ fixed frequency and the $C, L_{1}, K_{12}$ design variables. The optimization conducted using the component values in TABLE I. except for the $L_{1}$ (treated as the design variable). By substituting the component values to the problem set (12), we obtained the objective function (16).

$$
f_{1}=\frac{f_{1 n}}{f_{d}} \quad f_{2}=\frac{f_{2 n}}{f_{d}}
$$

where

$$
\begin{aligned}
& f_{1 n}=-\left(4.25 \cdot 10^{31} C^{2} K_{12}^{2} L_{1}\right) \\
& f_{2 n}=-\left(9.73 \cdot 10^{31} C^{2} K_{12}^{2} L_{1}\right) \\
& f_{d}=\left(4.23 \cdot 10^{41} C^{2} K_{12}^{4} L_{1}^{2}-4.23 \cdot 10^{41} C^{2} K_{12}^{2} L_{1}^{2}\right. \\
& +2.82 \cdot 10^{32} C^{2} K_{12}^{2} L_{1}+1.06 \cdot 10^{41} C^{2} L_{1}^{2}+5.96 \cdot 10^{25} C^{2} \\
& \left.+2.33 \cdot 10^{26} C K_{12}^{2} L_{1}-1.17 \cdot 10^{26} C L_{1}+32271604091.3\right)
\end{aligned}
$$

The optimization generates single solutions shown in TABLE III. Using the optimum value in capacitance, primary coil inductance, and coupling coefficients in TABLE III, we performed the LTSPICE AC analysis with a 1-Volts voltage source. The results are plot using Python as in FIG. 7.

TABLE III. FIg. 5 DeCISION MAKING Results

\begin{tabular}{|c|c|c|c|c|}
\hline \multicolumn{2}{|c|}{ Objective Values } & \multicolumn{3}{|c|}{ Design Values } \\
\hline $\begin{array}{c}f_{1} \\
\text { (Watt) }\end{array}$ & $\begin{array}{c}f_{2} \\
\text { (Watt) }\end{array}$ & $\begin{array}{c}C \\
(\mathrm{~F})\end{array}$ & $\begin{array}{c}L_{1} \\
\text { (Henry) }\end{array}$ & $K_{12}$ \\
\hline 0.09 & 0.15 & $56.2 \mathrm{p}$ & $10.65 \mu$ & 0.19 \\
\hline
\end{tabular}

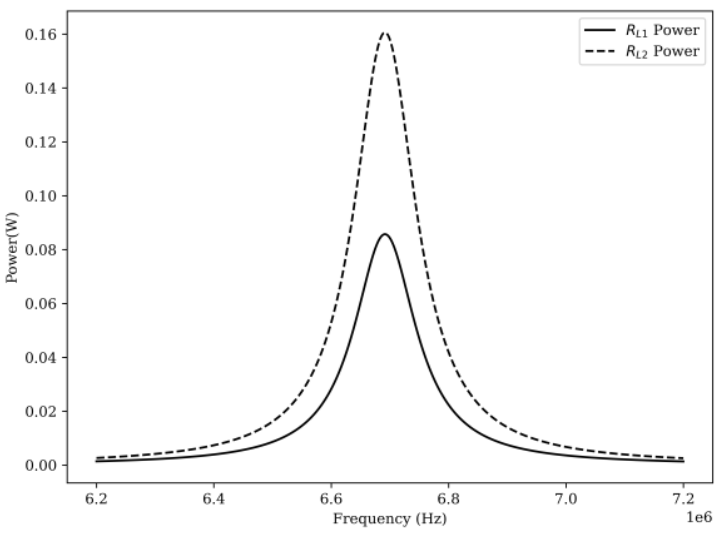

Fig. 7. LTSPICE Results Plotted using Python for obtained design values in TABLE III. with $6.78 \mathrm{MHz}$ Frequency.

\section{Optimization Results with Capacitance and Frequency Design Variables.}

In this sub-section, we present results when the optimization considers only two design variables: capacitance $(C)$ and frequency $(\omega)$. The numerical values for other components are shown in TABLE IV.

TABLE IV. COMPONENT VALUES FOR OPTIMIZATION WITH CAPACITANCE AND FREQUENCY AS DESIGN VARIABLES

\begin{tabular}{|l|c|c|c|}
\hline Parameter & Value & Parameter & Value \\
\hline$L_{1}$ & $22 \mu \mathrm{H}$ & $K_{2}$ & 0.12 \\
\hline$L_{2}$ & $11 \mu \mathrm{H}$ & $K_{3}$ & 0 \\
\hline$L_{3}$ & $9 \mu \mathrm{H}$ & $R_{s}$ & $1 \Omega$ \\
\hline$R_{1}=R_{2}=R_{3}$ & $0.01 \Omega$ & $R_{L 1}$ & $8 \Omega$ \\
\hline$K_{1}$ & 0.09 & $R_{L 2}$ & $15 \Omega$ \\
\hline
\end{tabular}

By substitute the component values from TABLE IV. to equation(13), we obtain the objective function in (17).

$$
f_{1}=\frac{f_{1 n}}{f_{d}} \quad f_{2}=\frac{f_{2 n}}{f_{d}}
$$

$f_{1 n}=-\left(C^{2} \omega^{4}\left(1.55 \cdot 10^{-21} \omega^{2}+4.33 \cdot 10^{-9}\right)\right)$

$f_{2 n}=-\left(C^{2} \omega^{4}\left(5.24 \cdot 10^{-21} \omega^{2}+2.78 \cdot 10^{-9}\right)\right)$

$f_{d}=C^{2} \omega^{2}\left(4.51 \cdot 10^{-30} \omega^{6}+1.54 \cdot 10^{-17} \omega^{4}+7.04 \cdot 10^{-6} \omega^{2}+14745.82\right)$

$-C \omega^{2}\left(4.21 \cdot 10^{-25} \omega^{4}+1.413 \cdot 10^{-12} \omega^{2}\right.$

$\left.+0.64)+9.8 \cdot 10^{-21} \omega^{4}+3.24 \cdot 10^{-8} \omega^{2}+14455.27\right)$

The optimization was performed using NSGA-II with 500 population size and 200 generations configuration. The results have 192 solutions, as presented in Fig. 8. 


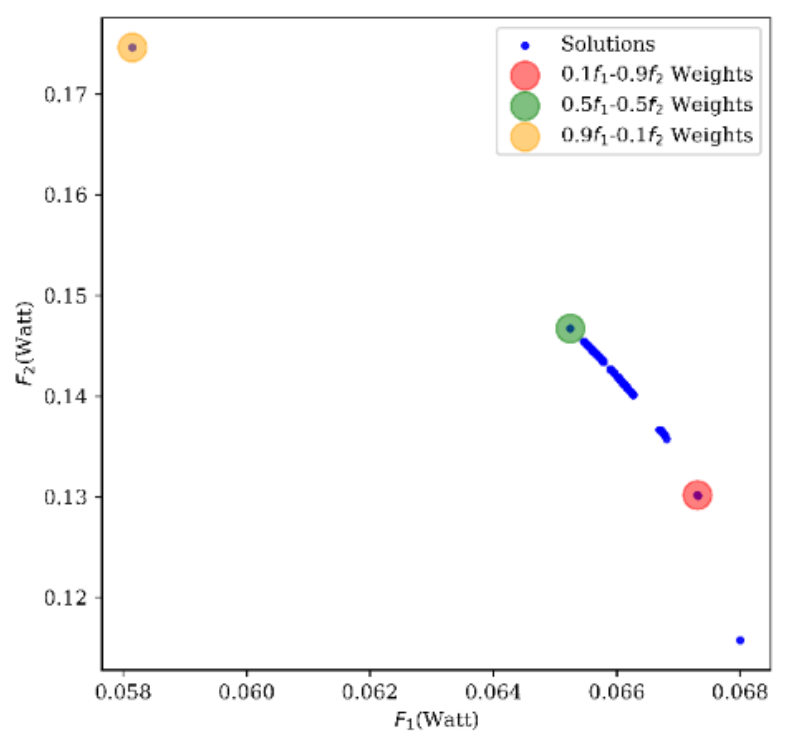

Fig. 8. Optimization Results for Objective Functions in equation (17) Using Numerical Values in TABLE IV.

TABLE V. Fig. 8 DECISION MAKING RESUltS

\begin{tabular}{|c|c|c|c|c|}
\hline \multirow{2}{*}{$\begin{array}{c}\text { Decision } \\
\text { Making }\end{array}$} & \multicolumn{2}{|c|}{ Objective Values } & \multicolumn{2}{|c|}{ Design Values } \\
\hline & $\begin{array}{c}f_{1} \\
\text { (Watt) }\end{array}$ & $\begin{array}{c}f_{2} \\
\text { (Watt) }\end{array}$ & $\begin{array}{c}C \\
(\mathrm{~F})\end{array}$ & $\begin{array}{c}\text { Frequency } \\
\text { (Hertz) }\end{array}$ \\
\hline $\begin{array}{l}\text { Pseudo- } \\
\text { Weight } \\
0.1 f_{1} \\
0.9 f_{2}\end{array}$ & 0.06 & 0.13 & $18.45 n$ & $251.93 \mathrm{k}$ \\
\hline $\begin{array}{l}\text { Pseudo- } \\
\text { Weight } \\
0.5 f_{1} \\
0.5 f_{2}\end{array}$ & 0.06 & 0.14 & $11.6 n$ & $317.95 \mathrm{k}$ \\
\hline $\begin{array}{l}\text { Pseudo- } \\
\text { Weight } \\
0.9 f_{1} \\
0.1 f_{2}\end{array}$ & 0.05 & 0.17 & $2.59 n$ & $674.74 \mathrm{k}$ \\
\hline
\end{tabular}

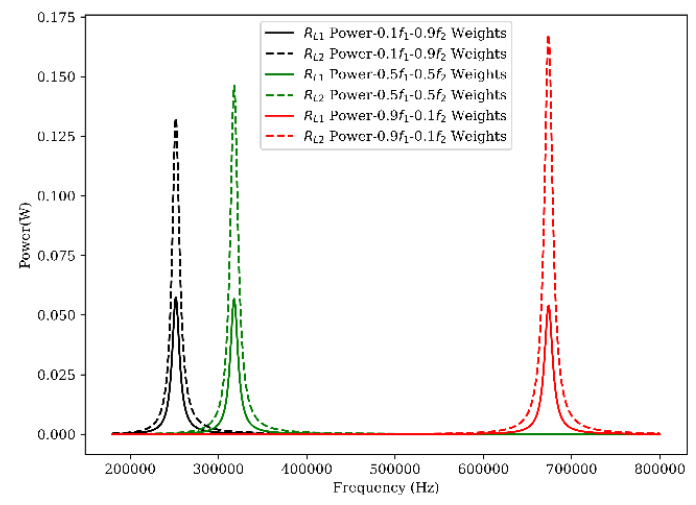

Fig. 9. LTSPICE Results Plotted using Python for obtained design values in 0

\section{The Proposed WPT Circuit with The Common WPT Circuit Comparison.}

This section performed the comparison of the proposed circuit in Fig. 1 with the common WPT circuit in Fig. 2 using the component configuration in TABLE VI. [5].

\section{TABLE VI. COMPONENT VALUES FOR SCENARIO 1}

\begin{tabular}{|c|c|}
\hline Parameter & Value \\
\hline$L_{1}=L_{2}=L_{3}$ & $22 \mu \mathrm{H}$ \\
\hline$R_{1}=R_{2}=R_{3}$ & $0.01 \Omega$ \\
\hline$M_{1}=M_{2}$ & $5 \mu \mathrm{H}$ \\
\hline$M_{3}$ & 0 \\
\hline$R_{s}$ & $1 \Omega$ \\
\hline$R_{L 1}=R_{L 2}$ & $8 \Omega$ \\
\hline
\end{tabular}

By substituting TABLE VI. to equation (9), we obtain the objective function (18). The $f_{1}$ and $f_{2}$ are equal since both receivers have identical component values. The performed optimization obtains $C=21.4 \mathrm{nF}$ and a frequency $=243.89 \mathrm{kHz}$ with $f_{1}=f_{2}=0.12$ Watt. The AC analysis (1-Volts voltage of the voltage source) simulation is plotted in Fig. 10 and shows a 0.12 -Watt power obtained by both $R_{L 1}$ and $R_{L 2}$.

$f_{1}=\frac{f_{1 n}}{f_{d}} \quad f_{2}=f_{1}$

$f_{1 n}=8 C^{2} \omega^{4}\left(1.21 \cdot 10^{-20} \omega^{2}+1.60 \cdot 10^{-9}\right)$

$f_{d}=C^{2}\left(9.11 \cdot 10^{-29} \omega^{8}+2.77 \cdot 10^{-17} \omega^{6}+2.11 \cdot 10^{-6} \omega^{4}+4199.26 \omega^{2}\right)$

$+C\left(-9.24 \cdot 10^{-24} \omega^{6}-2.59 \cdot 10^{-12} \omega^{4}-0.18 \omega^{2}\right)$

$+2.34 \cdot 10^{-19} \omega^{4}+6.21 \cdot 10^{-8} \omega^{2}+4116.51$

With common WPT circuit in Fig. 2, we use the idea of resonance calculations (8) by configuring $C_{1}=C_{2}=C_{3}=110$ $\mathrm{nF}$ and frequency $=102 \mathrm{kHz}$. Then, we perform the simulation using The LTSPICE AC analysis (1-Volts voltage of the voltage source) with frequency swept from $50-150 \mathrm{kHz}$. The results are plotted in Fig. 11, where 0.10-Watt power is obtained by the $R_{L 1}$ and $R_{L 2}$. 


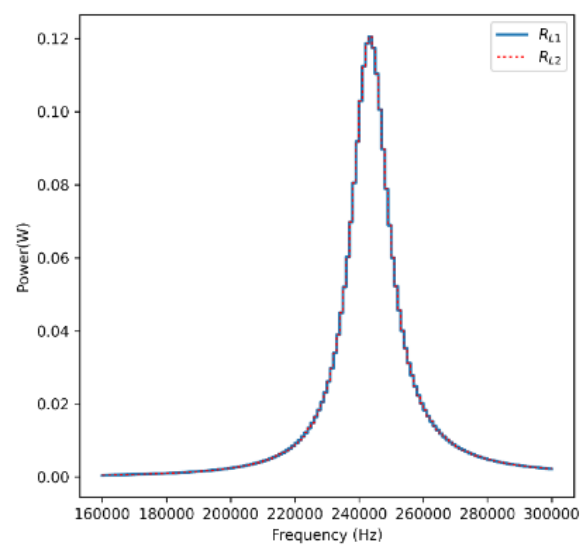

Fig. 10. Power at $R_{L 1}$ and $R_{L 2}$ using proposed circuit and optimization method with $C=21.4 \mathrm{nF}$ and freq $=243.89 \mathrm{kHz}$ (Obtained from LTSPICE simulations)

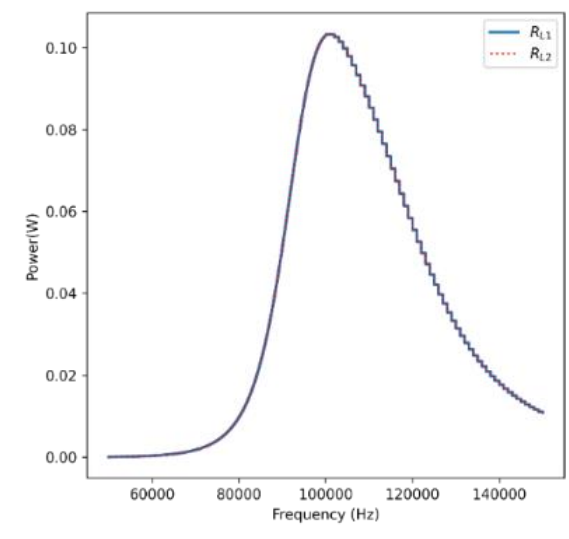

Fig. 11. Power at $R_{L 1}$ and $R_{L 2}$ in Fig.2 circuit and idea of resonance calculation using $C_{1}=C_{2}=C_{3}=110 \mathrm{nF}$. (Obtained from LTSPICE simulations)

\section{DISCUSSIONS}

This study has presented a high power WPT system using single capacitor compensation on the primary circuit. The objective function is obtained through the system model and tested using several design spaces to answer the WPT design challenges. The optimization has been performed with PyMOO tools with NSGA-II using 500 populations and 200 generations. Since the optimization conducted using two objective functions, the obtained solutions can be more than one. Therefore, a decision making using fair $0.5 f_{1}-0.5 f_{2}$ pseudo-weight is chosen. If there are changes in priority due to the system requirements, the weight can be changed as in Fig. 8. Then the LTSPICE simulation conducted using the $\mathrm{AC}$ analysis using 1 -Volt source voltage and plotted using Python programming.
TABLE VII. DECISION MAKING RESULTS COMPARISON IN DIFFERENT DESIGN SPACES SELECTION

\begin{tabular}{|l|c|c|c|}
\hline \multirow{2}{*}{ Design Spaces } & \multicolumn{2}{|c|}{$\begin{array}{c}\text { Optimum Objective } \\
\text { Values }\end{array}$} & \multirow{2}{*}{$\begin{array}{c}\text { Optimal Design } \\
\text { Values }\end{array}$} \\
\cline { 2 - 3 } & $\begin{array}{c}f_{1} \\
\text { (Watt) }\end{array}$ & $\begin{array}{c}f_{2} \\
\text { (Watt) }\end{array}$ & \\
\hline $\begin{array}{l}\text { C, } \omega, K_{12} \\
\text { Pseudo-weight }=0.5 \quad f_{1}\end{array}$ & 0.09 & 0.15 & $\begin{array}{c}\mathrm{C}=10.2 \mathrm{nF} \\
\text { freq }=343.01 \mathrm{kHz} \\
K_{12}=0.16\end{array}$ \\
$-0.5 f_{2}$ & & & $\begin{array}{c}\mathrm{C}=56.2 \mathrm{pF} \\
L_{1}=10.65 \mu \mathrm{H} \\
K_{12}=0.19\end{array}$ \\
\hline C, $L_{1}, K_{12}$ & 0.09 & 0.15 & \\
\hline C, $\omega$ & & & $\begin{array}{c}\mathrm{C}=11.6 \mathrm{nF} \\
\text { Preq }=317.95 \mathrm{kHz}\end{array}$ \\
\hline$-0.5 f_{2}$ & 0.06 & 0.14 & \\
\hline
\end{tabular}

The optimization results on the three design space variables $\left(C, \omega, K_{12}\right.$ and $C, L_{1}, K_{12}$ ) show that all solutions have a 0.24 -Watt (addition from $f_{1}$ and $f_{2}$ ). The conclusion for both optimization results has been shown in TABLE VII. By comparing the total optimum objective values in $f_{1}$ and $f_{2}$ for every solution on design variables scenario, it can be concluded that the optimum value can be obtained from the three choices of design spaces, which are $C, \omega, K_{12}$ and $C, L_{1}, K_{12}$.

Compared with the common WPT circuit, this study conducted a comparison using the same component values except for the capacitor and frequency components. Our results show higher power absorbed by both receivers. The common WPT circuit with the idea of resonance and selected capacitor and frequency values are not working on the operational point conditions. Therefore, even though resonance can be calculated using (8), an optimal operating points search should be considered in any kind of circuit to obtain high power.

The proposed approach has currently focused on a series-series WPT circuit from the optimization of components design variables, whereas there are possibilities that higher power can be achieved at some operating points on other forms of architecture. In the future, the mathematical model in the other forms of architecture may be derived using our approach in obtaining transfer function. Then, the optimal high-power operating points can be compared between architectures in order to get the highest power WPT system.

Our current system is supplied by one voltage source with one frequency. In the future, it is also important to consider whether each of the load receiver able to absorb power delivered using many frequencies from many voltage sources. Therefore, our current system model should be improved by adding multi-frequency source analysis.

\section{CONCLUSIONS}

In this paper, we have proposed a high-power WPT system with single capacitor compensation on the primary side for 
multiple receivers. Our approach has been initialized with the derivation of the mathematical model of the system consisting of two load receivers and transfer functions from the input voltage to the average powers at two receivers are used in the objective function. The problem sets have been defined from the selection of design variables and optimized using NSGA-II. The optimization has been conducted in three WPT design variables selection, which are: 1) Optimal operating capacitance, frequency, and coupling. 2) Optimal operating capacitance, primary coil inductance, and coupling. 3) Optimal capacitance and frequency.

The optimization results have shown that the three design space variables selection $\left(C, \omega, K_{12}\right.$ and $\left.C, L_{1}, K_{12}\right)$ have a maximum power achieved (0.24-Watt). Based on the simulation, the proposed system load receivers absorbed higher power than the common WPT circuit using the idea of resonance by $20 \%$. Therefore, our proposed system works at optimal operating points, even though it lacks symmetry and does not using the ideas of resonance.

\section{REFERENCES}

[1] L. Sun, D. Ma and HoujunTang, "A review of recent trends in wireless power transfer technology and its applications in electric vehicle wireless charging," Renewable and Sustainable Energy Reviews, vol. 91, pp. 490-503, 2018.

[2] H.-J. Kim, H. Hirayama, S. Kim, K. J. Han, R. Zhang and J.-W. Choi, "Review of Near-Field Wireless Power and Communication for Biomedical Applications," IEEE Access, vol. 5, pp. 21264 - 21285, 2017.

[3] S. Kokosis, E. Gati, N. Patsourakis and S. Manias, "Comparative evaluation of $\mathrm{GaN}$ transistors and $\mathrm{Si}$ MOSFETs for use in inductive power transfer systems of biomedical implantable devices," WSEAS Transactions on Power Systems, vol. 14, pp. 172-180, 2019.

[4] M.-F. STAN, N. FIDEL, I. MINA and A.-G. HUSU, "Improvement of Wireless Power Transfer Efficiency for Home Electronics and Appliances with the Use of SMD Components," in 2018 10th International Conference on Electronics, Computers and Artificial Intelligence (ECAI), Iasi, Romania, 2018.

[5] W. Cai, D. Ma, H. Tang, X. Lai, X. Liu and L. Sun, "Highly Efficient Target Power Control for Two-Receiver Wireless Power Transfer Systems," Energies, vol. 11, no. 10, p. 2726, 2018.

[6] K. Zhuo, B. Luo, Y. Zhang and Y. Zuo, "Multiple receivers wireless power transfer systems using decoupling coils to eliminate cross-coupling and achieve selective target power distribution," IEICE Electronics Express, vol. 16, no. 18, p. 20190491, 2019.

[7] M. WAGIH, A. KOMOLAFE and B. ZAGHARI, "Dual-Receiver Wearable 6.78 MHz Resonant Inductive Wireless Power Transfer Glove Using Embroidered Textile Coils," IEEE Access, vol. 8, pp. 24630-24642, 2020.
[8] W. Cai, D. Ma, X. Lai, K. H. H. Tang and J. Xu, "Time-Sharing Control Strategy for Multiple-Receiver Wireless Power Transfer Systems," Energies, vol. 13, no. 3, p. 599, 2020.

[9] X. Wei, Z. Wang and H. Dai, "A Critical Review of Wireless Power Transfer via Strongly Coupled Magnetic Resonances," Energies, vol. 7, no. 7, pp. 4316-4341, 2014.

[10] S. Y. R. Hui, W. Zhong and C. K. Lee, "A Critical Review of Recent Progress in Mid-Range Wireless Power Transfer," IEEE Transactions on Power Electronics, vol. 29, no. 9, 2014.

[11] X. Mou and H. Sun, "Wireless Power Transfer: Survey and Roadmap," in 2015 IEEE 81st Vehicular Technology Conference (VTC Spring), Glasgow, 2015.

[12] T. C. Beh, M. Kato, T. Imura, S. Oh and Y. Hori, "Automated Impedance Matching System for Robust Wireless Power Transfer via Magnetic Resonance Coupling," IEEE Transactions on Industrial Electronics, vol. 60, no. 9, pp. 3689-3698, 2013.

[13] M. Frivaldsky, V. Jaros, P. Spanik and M. Pavelek, "Control system proposal for detection of optimal operational point of series-series compensated wireless power transfer system," Electrical Engineering, vol. 102, p. 1423-1432, September 2020.

[14] K. Yamaguchi, T. Hirata, Y. Yamamoto and I. Hodaka, "Resonance and efficiency in wireless power transfer system," in WSEAS Transactions on Circuits and Systems, 2014.

[15] X. Liu, L. Clare, X. Yuan, C. Wang and J. Liu, "A Design Method for Making an LCC Compensation Two-Coil Wireless Power Transfer System More Energy Efficient Than an SS Counterpart," Energies, vol. 10, no. 9, p. 1346, 2017.

[16] C. Cheng, Z. Zhou, W. Li, C. Zhu, Z. Deng and C. C. Mi, "A Multi-Load Wireless Power Transfer System With Series-Parallel-Series Compensation," IEEE Transactions on Power Electronics, vol. 34, no. 8, pp. 7126 - 7130, 2019.

[17] H. Qiang, X. L. Huang, L. Tan, Q. Ji and J. M. Zhao, "Achieving maximum power transfer of inductively coupled wireless power transfer system based on dynamic tuning control," Science China Technological Sciences, vol. 55, p. 1886-1893, 2012.

[18] T. Hirata, K. Yamaguchi and I. Hodaka, "A symbolic equation modeler for electric circuits," ACM Communications in Computer Algebra, vol. 49, no. 3, pp. 1932-2240, 2015.

[19] K. Yamaguchi, T. Hirata and I. Hodaka, "A general method to parameter optimization for highly efficientwireless power transfer," International Journal of Electrical and Computer Engineering, vol. 6, no. 6, pp. 3217-3221, 2016.

[20] K. Yamaguchi, T. Hirata and I. Hodaka, "High Power Wireless Power Transfer Driven by Square Wave Inputs," in Genetic and Evolutionary Computing. GEC 2015. 
Advances in Intelligent Systems and Computing, Yangon, Myanmar, 2015.

[21] W. Zhang and C. C. Mi, "Compensation Topologies of High-Power Wireless Power Transfer Systems," IEEE Transactions on Vehicular Technology, pp. 4768 - 4778, 2015.

[22] S. G. Manuele Bertoluzzo and E. Sieni, "Automatic Optimization of the Compensation Networks of a Wireless Power Transfer System," Energies, vol. 13, no. 20, 2020.

[23] S. Chatterjee, A. Iyer, C. Bharatiraja, I. Vaghasia and V. Rajesh, "Design Optimisation for an Efficient Wireless Power Transfer System for Electric Vehicles," Energy Procedia, vol. Volume 117, pp. 1015-1023, 2017.

[24] D.-W. Seo, J.-H. Lee and a. H.-S. Lee, "Optimal Coupling to Achieve Maximum Output Power in a WPT System," IEEE TRANSACTIONS ON POWER ELECTRONICS, vol. 31, no. 6, pp. 3994-3998, 2016.

[25] Y. Li, S. Jiang, X.-L. Liu, Q. Li, W.-H. Dong, J.-M. Liu and $\mathrm{X}$. Ni, "Influences of Coil Radius on Effective Transfer Distance in WPT System," IEEE Access, vol. 7, pp. 125960-125968, 2019.

[26] Y. Yang, J. Cui and X. Cui, "Design and Analysis of Magnetic Coils for Optimizing the Coupling Coefficient in an Electric Vehicle Wireless Power Transfer System," Energies, vol. 13, p. 4143, 2020.

[27] L. Gu, G. Zulauf, A. Stein, P. A. Kyaw, T. Chen and J. M. R. Davila, "6.78-MHz Wireless Power Transfer With Self-Resonant Coils at 95\% DC-DC Efficiency," IEEE Transactions on Power Electronics, vol. 36, no. 3, pp. 2456-2460, March 2021.

[28] J. Song, M. Liu and C. Ma, "Analysis and Design of A High-Efficiency $6.78-\mathrm{MHz}$ Wireless Power Transfer System With Scalable Number of Receivers," IEEE Transactions on Industrial Electronics, vol. 67, no. 10, pp. 8281-8291, 2020.

[29] M. Wagih, A. O. Komolafe and B. Zaghari, "Position Independent Wearable 6.78 MHz Near-Field Radiative Wireless Power Transfer using Electrically-Small Embroidered Textile Coils," in 2019 19th International Conference on Micro and Nanotechnology for Power Generation and Energy Conversion Applications (PowerMEMS), 1-5, 2019.

[30] J. Blank and K. Deb, "Pymoo: Multi-Objective Optimization in Python," IEEE Access, vol. 8, pp. 89497-89509, 2020.

[31] K. Deb, A. Pratap, S. Agarwal and T. Meyarivan, "A fast and elitist multi-objective genetic algorithm: NSGA-II," IEEE Transactions on Evolutionary Computation, vol. 6, no. 2, pp. 182-197, 2002.

[32] K.Deb, "Multi-Objective Optimization Using Evolutionary Algorithms:An Introduction," in Multi-objective evolutionary optimisation for product design and manufacturing, London, Springer, 2011, pp. 3-34.

\section{Contribution of individual authors to the creation of a scientific article (ghostwriting policy)}

\section{Author Contributions:}

Ideas and Conceptualization, S.R.A and I.H;

Methodology, S.R.A and I.H;

Python programming and visualization: S.R.A;

System Model and Formal Analysis, S.R.A, I.H;

Optimization and Simulation, S.R.A, I.H;

Draft preparation, S.R.A;

Validation, S.R.A and I.H.;

Review and Supervision, I.H;

\section{Creative Commons Attribution License 4.0 (Attribution 4.0 International, CC BY 4.0)}

This article is published under the terms of the Creative Commons Attribution License 4.0 https://creativecommons.org/licenses/by/4.0/deed.en US 